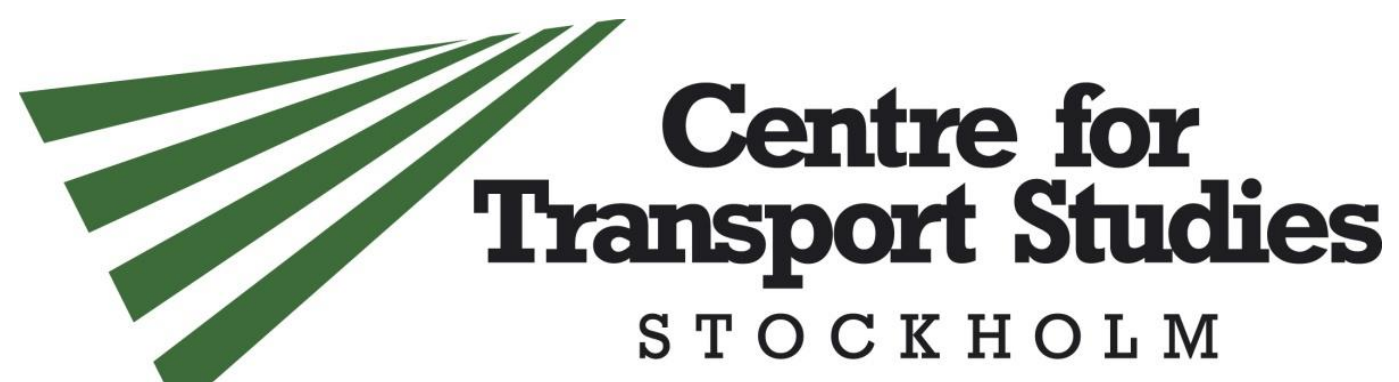

\title{
Public Transport: One mode or several?
}

\author{
Juan Manuel Lorenzo Varela - CTS \\ Maria Börjesson - CTS \\ Andrew Daly - CTS / ITS, Leeds / RAND Europe
}

CTS Working Paper 2017:6

\begin{abstract}
This paper develops a methodology for testing and implementing differences in preferences for a set of public transport modes, relating to observed and unobserved attributes, in state-of-practice large-scale travel demand models. Results of a case study for commuters in the Stockholm public transport system suggest that there are preference differences among public transport modes, and that they are captured by unobserved attributes. Surprisingly, we found no evidence for differences proportional to the in-vehicle time, suggesting that characteristics of in-vehicle time in different public transport modes, such as comfort, are valued equally by the travellers. We also found that the value of time is higher for auxiliary modes than for the main mode, and that the unobserved preference for metro is highest and the preference for light rail lowest.
\end{abstract}

Keywords: Choice behaviour; Generalised travel cost; Unobserved preferences; Rail factor; Demand forecast. 
Public Transport: One mode or several? 


\section{INTRODUCTION}

There is a political preference for rail-based Public Transport (PT) modes over bus services. Decision makers in many European countries seem to prefer rail over bus services, claiming that travellers prefer services operating on tracks, referring to this as a "rail factor". Moreover, property developers often claim that metro investments increase the land values over and above what a bus system with equal capacity and travel times would. If travellers' preferences differ between PT modes, the treatment of them as the same mode in transport models translates into biased parameter estimates and model predictions. Such bias would then propagate to all types of policy analyses including Cost Benefit Analysis (CBA).

A higher preference for rail-based PT modes is to some extent supported by studies in psychology, transport modelling and economics. For instance, Eliasson (2016) found that accessibility by metro increases the property prices of apartments in Stockholm more than accessibility by bus. In the transport modelling field, Ben-Akiva and Morikawa (2002) explore differences in the preference for rail and bus services in two case studies. They estimate choice models on combined revealed preference (RP) and stated preference (SP) data. The utility function for PT includes dummy variables for each PT mode. The alternative specific constants indicate that metro is most preferred, followed by bus and commuter train. However, level-of-service (LoS) parameters do not differ significantly across PT modes. Scherer et al. (2012) includes a metaanalysis of German and Swiss studies focusing on user perceptions and mental representation of train, tram, and bus. They conclude that there is a rail factor, loaded with emotional and social attributions.

In this study, we develop a method for testing whether travellers' preferences for PT differ between modes in a state-of-practice large-scale transport model. We show how to implement such differences in the transport model. We find that in the Stockholm public transport system, travellers' preferences vary across PT modes and travel time components. We also find that the value of time is higher for auxiliary modes than for the main mode, consistent with earlier literature (see the meta-study by Wardman, 2004).

We expand the analysis by Ben-Akiva and Morikawa, by introducing a more flexible model specification tailored to capture differences in observed and unobserved preferences between PT modes. The models are specified to capture the systematic difference in unobserved preferences among PT modes (alternative-specific constants), the correlation of the random errors across the PT modes, and the systematic differences in preference for LoS variables and 
travel time components. We introduce the definition of main mode, in cases where more than one PT mode is used within the same trip. To our knowledge, no previous study on large-scale models has in this way systematically explored how the preference differs across PT modes in all these dimensions, although large-scale transport model prediction is the cornerstone of transport appraisal.

We stress that the aim of this paper is primarily to develop an approach for testing and implementing systematic differences in preferences among PT modes. Such differences are likely to vary across transport systems, since customer preferences derive from perceptions and beliefs which are influenced by local conditions and cultures (Scherer 2010). Hence, empirical evidence might differ across transport networks and over time.

The rest of the paper is structured as follows: Section 2 presents the modelling framework and hypotheses tested. Section 3 provides an overview of the data. Section 4 discusses the application of the framework. Section 5 presents some properties of the models obtained and Section 6 concludes.

\section{METHOD}

We begin by defining a state-of-practice mode choice model, specified as a Multinomial Logit model (MNL). We include a sub-set of PT modes as well as a number of other modes. The utility of alternative $\mathrm{j}$ is defined as

$$
U_{j}=\sum \beta_{i j} x_{i j}+A S C_{j}+\varepsilon_{j}
$$

where $\beta_{\mathrm{ij}}$ are parameters, $\mathrm{x}_{\mathrm{i}}$ are explanatory variables, $\mathrm{ASC}_{\mathrm{j}}$ is the alternativespecific constant, and $\varepsilon_{\mathrm{j}}$ is the random variation of the unobserved variables, assumed independent across alternatives. Preference differences across PT modes $\mathrm{j}$ can be represented in this model by PT mode specific constants - ASC $_{j}{ }^{-}$, systematic differences in preference for observable LoS variables $-\beta_{\mathrm{ij}}-$, and in the random error $\varepsilon_{\mathrm{j}}$. Different alternative-specific constants and level-of-service parameters can be implemented in the model even if all PT modes are modelled as one alternative with one utility function in the choice model. However, when modelling all PT modes as one single alternative, with the same utility function, the random error is assumed to be the same for all PT modes. In contrast, modelling the PT modes as different alternatives in an MNL model implies that the errors $\varepsilon_{\mathrm{j}}$ are independent. If the error terms of the PT alternatives are correlated, but independent from the error terms of the other modes, this can be modelled in a Nested Logit (NL) model, including the PT mode alternatives within the same nest.

In Section 2.3 we describe how we systematically test for preference differences captured by the alternative-specific constants, the LoS-parameters and the 
random errors. This is done by estimating a series of increasingly flexible modes. In Section 2.2 we described the statistical tests that we apply. Since some travellers use several PT modes within one trip, we need to define the main PT mode of each trip. Section 2.1 describes the main mode definition.

\subsection{Main mode definition}

In order to properly model different PT modes, a main mode needs to be defined. Unless one defines a main mode, then, as in Ben-Akiva and Morikawa 2002, the model estimation needs to be constrained to use "pure" observations only - observations where only one PT mode is used - neglecting all PT intermodal observations. Hence, in order to use as much information as possible to investigate nuances in the preference for different PT alternatives, we need to define a main mode.

In this study we defined the main mode of each trip as the mode used for the longest distance. We applied this definition for two reasons. First, a definition based on distance, as opposed to travel time, will not change with traffic conditions. Second, it is consistent with how the main mode was defined in the national travel survey data used to estimate the model, allowing us to crosscheck whether the user-reported main mode and the main mode imputed from network attributes are the same. Observations where the main modes differ are discarded for this study.

Still, the concept of main mode is essentially an artificial construct. We acknowledge that other main mode definitions are possible, for instance a hierarchical definition, and that the definition of the main mode might influence our results. To test the robustness of the main mode definition against the chosen definition, we therefore run a model with only "pure observations", observing consistent behaviour. Results for this test are given in Appendix 2.

\subsection{Statistical test}

For much of our hypothesis testing, we use the Likelihood Ratio Test (LRT) to compare the goodness of fit of two models, when one is a restricted version of the other; meaning that the restricted model can be obtained by imposing restrictions on parameters in the unrestricted model.

The LRT statistic is chi-squared distributed, influenced by the number of restrictions between the models; where the number of restrictions is the number of constraints imposed on the unrestricted model to obtain the restricted model.

$$
\mathrm{LRT}=-2\left[\mathcal{L}_{\mathrm{R}}(\widehat{\theta})-\mathcal{L}_{\mathrm{U}}(\widehat{\theta})\right] \sim \chi_{\mathrm{DOF}}^{2}
$$

Further, to test whether a subset of the choice set can be treated as a single alternative, we use the Cramer and Ridder LRT, formulated by Cramer and Ridder (1991). This hypothesis requires a different test, because the models have different number of utility functions; hence, the restricted model can no 
longer be obtained by imposing restrictions on parameters in the unrestricted model.

Cramer and Ridder (1991) shows that testing whether a sub-set of the choice set can be treated as a single alternative is equivalent to testing whether the regressor coefficients (all except the alternative-specific constants) are equal across sub-alternatives. Therefore, the test statistic (2) can be used also to test whether modelling the subset of the alternatives as different alternatives is a significant improvement. Then, let $\mathcal{L}_{U}$ be the log-likelihood of the model assuming that the set of sub-alternatives are different alternatives, and let $\mathcal{L}_{\mathrm{R}}$ be the log-likelihood of the restricted model,

$$
\mathcal{L}_{\mathrm{R}}=\sum n_{s_{i}} \log n_{s_{i}}-n_{s} \log n_{s}+\log \widehat{L_{p}}
$$

where $\log \widehat{L_{p}}$ is the log-likelihood of the model assuming a single alternative, $n_{s}$ is the total number of observations choosing the set of sub-alternatives to be merged, and $n_{s_{i}}$ is the number of observations choosing alternative $i$.

$$
n_{s}=\sum n_{s_{i}}
$$

Equation (2) can then be applied to test the significance of the restriction, with the degrees of freedom determined by the number of parameters constrained across the alternatives.

\subsection{Hypotheses and Models}

As a starting point, we define a state-of-practice large-scale mode choice model including commuting and education trips, with utility function defined by (1). It includes the alternatives PT (with the sub-alternatives metro, commuting train, bus and tram as one single alternative), car driver, car passenger, walk and cycle. The observed part of the utility function for PT includes In-Vehicle Time (IVT), initial waiting time, access/egress time, transfer penalties and trip cost. The utility functions for the car alternatives include travel time and travel cost, and dummy variables indicating car ownership and gender. The car driver alternative also includes a variable indicating car competition in the household. A full description of the model specification is given in Appendix 1.

Now, we formulate a sequence of hypotheses regarding the model specification and set up models to test them using the statistical tests defined in Section 2.2. Detailed results of the testing are presented in Section 4.

A key issue is whether to model the different public transport as a single alternative or as separate alternatives. As described in Section 2.1., this depends on whether all or some of the unobserved preferences for the PT modes, captured by the random error, are equal. If they are independent, the PT modes should be modelled as different alternatives in an MNL model, if they are identical, they should be modelled as a single alternative, and if they are correlated, they should be modelled as nested alternatives in a NL model. There 
are reasons why the error terms of the PT modes should be equal: they share several unobserved attributes, comfort, and characteristics, they are all public transport. However, it is also possible that they are different, for instance since the comfort, crowding and reliability may be different.

To explore the correlation of the random errors, we set up three hypothesis tests concerning the error term assumptions. Hypothesis 1 tests the assumption that the error terms of the PT modes are correlated against the assumption that they are identical. It is tested by estimating a Mixed Logit (ML) and comparing it to a MNL model. Hypothesis 2 is similar but tests the assumption that the random errors are independent against the assumption that they are identical, applying MNL models only. Hypothesis 6 tests whether the random error terms of the PT modes are correlated against the assumption that they are independent. It is tested by testing a NL model against an MNL model.

\section{Hypothesis 1 - Public Transport modes have identical random errors.}

The null hypothesis is that the random errors are identical across PT modes. We test this null hypothesis, under the assumption that all estimated parameters are constant across PT modes. We test a Mixed Logit (ML) model allowing for correlation of the error term of the PT modes against a MNL model assuming that the random errors are identical across PT modes.

- Model 1: All PT modes are modelled as a single alternative - the logistic random error $v_{P T}$ is shared among all PT main modes. The ASC and the normally distributed random errors $\left(\varepsilon_{\mathrm{j}}\right)$ are specific for each PT mode $\mathrm{j}$. Other LoS parameters are constrained to be constant across all PT modes. This ML model has utility functions defined by

$$
\mathrm{U}_{\mathrm{PT}}=\sum \mathrm{ASC}_{\mathrm{j}}+\sum\left(\beta_{\mathrm{i}} \mathrm{x}_{\mathrm{i}}\right)+\sum \varepsilon_{\mathrm{j}}+v_{\mathrm{PT}} \text {. }
$$

- Model 2: Same as model 1 but all PT modes are now assumed to share the random errors $\left(\varepsilon_{\mathrm{j}}\right)$, and they are therefore absorbed by the shared error $\nu_{\mathrm{PT}}$. Model 1 thus collapses to a MNL, with utility functions defined by

$$
\mathrm{U}_{\mathrm{PT}}=\sum \mathrm{ASC}_{\mathrm{j}}+\sum\left(\beta_{\mathrm{i}} \mathrm{x}_{\mathrm{i}}\right)+v_{\mathrm{PT}}
$$

As we will see in Section 4, the variances of the PT mode specific random errors $\varepsilon_{\mathrm{j}}$ are significantly different from zero. A LRT also shows that the ML model has a significantly better model fit. This means that we can reject the null hypothesis that the random errors are identical across PT modes, at all reasonable confidence levels.

Hypothesis 2 - Public Transport modes have identical random errors. 
We define two multinomial logit models, one that models PT modes as one alternative, and other where PT modes are modelled as different alternatives, and we apply the Cramer and Ridder LRT presented in Section 2.2. Note that this time, the restricted model cannot be obtained by imposing restrictions on the parameter coefficients as done to test hypothesis 1. As we will see in Section 4 , the result supports the need to model PT as different alternatives and therefore to reject this hypothesis.

\section{Hypothesis 3 - The preference for travel time is equal for main and auxiliary modes}

Here we test whether users have equal preference for spending time in the main and the auxiliary modes. We remind the reader the definition of main mode as the mode used for the longest trip segment; consequently, an auxiliary mode is any other PT mode used in the trip which is not the main mode.

- Model 3: Is the equivalent version of model 1, but translated into a MNL model. This model assumes that the LoS parameters are constant across PT alternatives.

$$
\mathrm{U}_{\mathrm{j}}=\mathrm{ASC}_{\mathrm{j}}+\sum\left(\beta_{\mathrm{i}} \mathrm{x}_{\mathrm{i}}\right)+\beta_{I V T}\left(\mathrm{IVT}_{j}+\mathrm{AUX}_{j}\right)+v_{j}
$$

- Model 4: Same as model 3 but we allow different IVT parameters for main and auxiliary modes

$$
\mathrm{U}_{\mathrm{j}}=\mathrm{ASC}_{\mathrm{j}}+\sum\left(\beta_{\mathrm{i}} \mathrm{x}_{\mathrm{i}}\right)+\beta_{I V T} \quad \mathrm{IVT}_{j}+\beta_{A u x} \mathrm{AUX}_{j}+v_{j}
$$

From this comparison we will show in the results section that the IVT parameters are significantly higher for the auxiliary modes than for the main mode. Hence, the LRT test rejects the hypothesis that preferences are equal for main and auxiliary modes.

\section{Hypothesis 4 - IVT preferences are equal across main modes.}

We test for preference differences in IVT across PT main modes. The null hypothesis is that the preference for IVT in the main mode is equal across main modes, independent of the mode. To test this hypothesis we use models 4 and 5.

- Model 5: Same as model 4 but we estimate separate IVT parameters for each main mode

$$
\mathrm{U}_{\mathrm{j}}=\mathrm{ASC}_{\mathrm{j}}+\sum\left(\beta_{\mathrm{i}} \mathrm{x}_{\mathrm{i}}\right)+\beta_{I V T_{j}} \mathrm{IVT}_{j}+\beta_{A u x} \mathrm{AUX}_{j}+v_{j}
$$


In this case, we cannot reject the null hypothesis that IVT preferences are equal across main modes.

\section{Hypothesis 5 - IVT preferences are equal among auxiliary modes.}

We test for preference differences in IVT across PT auxiliary modes. The null hypothesis is that IVT in the auxiliary modes is perceived equally, independent of the mode. To test this hypothesis, and to be consistent with the findings of the previous section, we use model 4 again, and model 6 .

- Model 6: Same as model 4 but we allow different parameters for each auxiliary mode IVT

$$
\mathrm{U}_{\mathrm{j}}=\mathrm{ASC}_{\mathrm{j}}+\sum\left(\beta_{\mathrm{i}} \mathrm{x}_{\mathrm{i}}\right)+\beta_{I V T} \quad \mathrm{IVT}_{j}+\beta_{A u x j} \mathrm{AUX}_{j}+v_{j}
$$

Again, we will see in the results section that we cannot reject the null hypothesis that preferences for travel time are equal across auxiliary modes.

\section{Hypothesis 6 - Public Transport modes have independent random errors.}

The final hypothesis tests the assumption that the random errors of the PT modes are correlated against the assumption that they are independent. We compare model 4 with model 7 , where we model the PT modes as different alternatives within a nest in a NL model, and other travel modes as alternatives in different nests. Figure 1 below shows the nesting structure implemented.

Figure 1,

Model 7 nesting Structure.

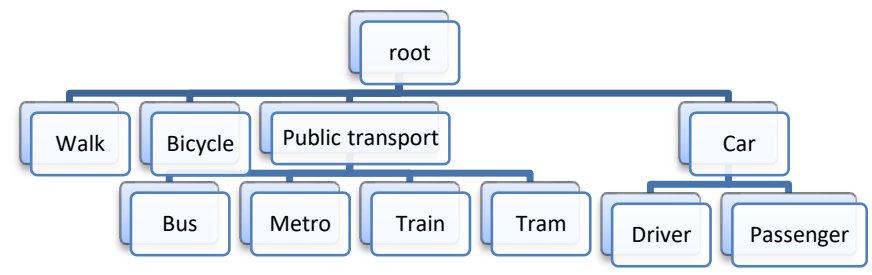

Model 7 showed that the hypothesis of no correlation was rejected by the data.

\section{DATA}

We estimate a mode choice model for commuting ${ }^{1}$ trips in Stockholm using PythonBiogeme. The model is estimated on 3818 trips, where the attributes of the chosen and non-chosen modes were computed using the assignment model in TransCad. The final sample includes 40.9\% PT trips (725 bus, 636 metro, 195 train and 7 tram), with $48.8 \%$ by car (driver and passenger) and $10.3 \%$ by walk and cycle. This distribution is broadly representative of commuting in Stockholm.

\footnotetext{
${ }^{1}$ Commuting trips in this study include work and education purposes.
} 
We estimate the models on the 2005/06 Swedish National Travel Survey. Respondents were randomly selected from the Sweden's population aged between 6 and 84 years. Twenty-seven thousand interviews were conducted, with a response rate of 68 per cent. The respondents were asked to report all trip made within a randomly selected survey day. For each reported trip they were asked to indicate their main travel mode (bus/train/metro/etc.), the travel mode used for each trip segment and their trip purpose, origin and destination addresses. Also, the survey contains socio-economic variables such as gender, individual income, household type, etc. which we have included in our models as shown in Table 12. Further details of the survey design are given by Trafikanalys (2007).

The data have to be processed in order to extract the variables necessary to define the utility functions. First the OD matrices were constructed, second the distances between each origin and destination reported were calculated, third the travel times for each alternative mode were computed, and fourth the travel costs were calculated for the chosen and the unchosen alternatives.

An assignment model was developed using the software TransCad to analyse the transport demand. In the assignment model, each zone was represented through a zone centroid, and each trip was modelled as a trip between the centroids of origin and destination zones. LoS variables were skimmed by mode from the assignment model, including: travel time, transfer time, waiting times, access/egress times, etc. If a main mode had more than one route available, the fastest route was selected.

There are eight mode alternatives in the data: car driver, car passenger, bus, metro, train, tram, bike, and walk. The car-driver mode is assumed to be available if the trip-maker has a driving licence, whilst the car passenger mode is always available. The bike mode is assumed to be available if the one-way home-to-work distance is less than $20 \mathrm{~km}$, while the walk mode is assumed to be available if the one-way home to work distance is less than $10 \mathrm{~km}$. Availability of the PT alternatives is determined as follows:

1. Different PT routes were identified using different network scenarios.

2. Looking at each route, the main mode is identified.

3. Main modes from step 2 form the PT choice set.

Table 1: Some descriptive statistics of the final sample.

\begin{tabular}{c|cccccccc} 
& Bicycle & Bus & $\begin{array}{c}\text { Car } \\
\text { Driver }\end{array}$ & $\begin{array}{c}\text { Car } \\
\text { Passenger }\end{array}$ & Metro & Train & Tram & Walk \\
\hline $\begin{array}{c}\text { Alternative } \\
\text { available }\end{array}$ & 677 & 3541 & 2690 & 3818 & 1489 & 679 & 208 & 621 \\
$\begin{array}{c}\text { Alternative } \\
\text { chosen }\end{array}$ & 57 & 725 & 1532 & 330 & 636 & 195 & 7 & 336 \\
$\begin{array}{c}\text { Average } \\
\text { distance in } \\
\text { km (Chosen } \\
\text { observations) }\end{array}$ & 2.6 & 12.5 & 15.0 & 10.3 & 9.4 & 25.3 & 6.7 & 1.9
\end{tabular}




\begin{tabular}{c|cccccccc}
$\begin{array}{c}\text { Average Age } \\
\text { user (years) }\end{array}$ & 33 & 31 & 43 & 21 & 34 & 37 & 37 & 26 \\
$\begin{array}{l}\text { Female users } \\
(\%)\end{array}$ & 42 & 58 & 35 & 59 & 57 & 60 & 64 & 54 \\
$\begin{array}{c}\text { Students (\%) } \\
\text { Students }\end{array}$ & 34 & 44 & 3 & 60 & 27 & 26 & 27 & 56
\end{tabular}

\section{RESULTS}

Parameter estimates, log-likelihood and goodness of fit results for the models estimated for hypothesis testing are reported in Table 8 . We can observe that all parameters regarding the modal attributes of travel time and costs affect the utility negatively in line with expectations.

The rest of the section presents detailed results for the hypothesis testing described in Section 2.

\section{Hypothesis 1 - Public Transport modes have identical random errors.}

Testing the hypothesis that all PT modes have the same random error requires models 1 and 2. Comparing these models, the LRT rejected the hypothesis that PT main mode alternatives have the same random error, see Table 3. Moreover, it can be observed in Table 2 that the estimated random variation of the unobserved attributes is statistically different from zero for three out of the four main modes.

Moreover, Table 8 shows that parameter estimates from models 1 and 2 are similar and that, ceteris paribus, metro is the most preferred alternative, followed by train, bus and tram. Special attention is drawn to the tram constant, which suggests a significant unobserved aversion to tram.

Table 2. Models 1 and 2 estimation results excerpt. ${ }^{2}$

\begin{tabular}{|c|c|c|c|c|c|c|c|}
\hline Model Num & \multicolumn{3}{|c|}{1} & \multicolumn{4}{|c|}{2} \\
\hline Model type & \multicolumn{3}{|c|}{ ML } & \multicolumn{4}{|c|}{ MNL } \\
\hline Draws & \multicolumn{3}{|c|}{1000} & \multicolumn{4}{|c|}{-} \\
\hline Estimated parameters & \multicolumn{3}{|c|}{33} & \multicolumn{4}{|c|}{29} \\
\hline Final log-likelihood: & \multicolumn{3}{|c|}{-2417.328} & \multicolumn{4}{|c|}{-2425.477} \\
\hline Rho-square & \multicolumn{3}{|c|}{0.063} & \multicolumn{4}{|c|}{0.060} \\
\hline Name & Value & Std err & t-test & Value & Std err & t-test & \\
\hline$A S C_{B U S}$ & -0.00332 & 0.228 & $-0.01 *$ & 0.164 & 0.176 & 0.93 & $*$ \\
\hline$A S C_{\text {METRO }}$ & 0.807 & 0.144 & 5.62 & 0.743 & 0.122 & 6.08 & \\
\hline$A S C_{T R A M}$ & -1.36 & 0.526 & -2.59 & -1.10 & 0.274 & -4.01 & \\
\hline
\end{tabular}

2 The mixed logit model was estimated by simulation using random draws; a large number of draws was used to avoid issues of simulation noise. 


\begin{tabular}{|c|c|c|c|c|c|c|}
\hline$A S C_{T R A I N}$ & 0.391 & 0.185 & 2.11 & 0.490 & 0.155 & 3.17 \\
\hline$\varepsilon_{B U S}$ & 1.56 & 0.430 & 3.63 & - & - & - \\
\hline$\varepsilon_{\text {METRO }}$ & 1.32 & 0.272 & 4.83 & - & - & - \\
\hline$\varepsilon_{T R A M}$ & 1.06 & 0.923 & $1.15 *$ & - & - & - \\
\hline$\varepsilon_{\text {TRAIN }}$ & 1.15 & 0.360 & 3.21 & - & - & - \\
\hline
\end{tabular}

* Parameter not statistically different from zero at $95 \%$ confidence.

Table 3 shows the comparison of models, and indicates that we can reject the hypothesis that PT main mode alternatives have the same random error at all reasonable confidence levels.

Table 3. LRT between models 1 and 2

\begin{tabular}{c|cccccc} 
& $\begin{array}{c}\text { Model } \\
\text { Number }\end{array}$ & Draws & $\begin{array}{c}\text { Final log- } \\
\text { likelihood }\end{array}$ & $\begin{array}{c}\text { Number of } \\
\text { parameters }\end{array}$ & $\begin{array}{c}\text { LRT } \\
\text { value }\end{array}$ & $\begin{array}{c}\text { LRT } \\
\text { P-value }\end{array}$ \\
\hline $\begin{array}{c}\text { Restricted } \\
\text { model }\end{array}$ & 2 & - & -2425.477 & 29 & & \\
$\begin{array}{c}\text { Unrestricted } \\
\text { model }\end{array}$ & 1 & 1000 & -2417.328 & 33 & 16.298 & 0.0026
\end{tabular}

\section{Hypothesis 2 - Public Transport modes have identical random errors.}

Testing this hypothesis requires models 2 and 3 . We compare these two models using the Cramer and Ridder LRT. The LRT value is 2020.72 for 12 degrees of freedom, implying that we can reject the model where PT is defined as a single alternative at all reasonable confidence levels.

Table 4. Cramer and Ridder LRT between models 2 and 3

\begin{tabular}{|c|c|c|c|c|c|c|c|c|c|}
\hline & \multirow{2}{*}{$\begin{array}{l}\text { Model } \\
\text { Number }\end{array}$} & \multirow{2}{*}{$\begin{array}{l}\text { Final log- } \\
\text { likelihood }\end{array}$} & \multicolumn{5}{|c|}{ Number of observations } & \multirow{2}{*}{$\begin{array}{c}\text { Test } \\
\text { value }\end{array}$} & \multirow{2}{*}{$\begin{array}{l}\text { CR_LRT } \\
\text { P-value }\end{array}$} \\
\hline & & & PT & Bus & Metro & Train & Tram & & \\
\hline $\begin{array}{l}\text { PT as one } \\
\text { alternative }\end{array}$ & 2 & 2425.477 & 1563 & - & - & & & 2020.717 & $<1 \mathrm{E}-05$ \\
\hline $\begin{array}{l}\text { PT as four } \\
\text { altermatives }\end{array}$ & 3 & $\begin{array}{c}- \\
2987.650\end{array}$ & - & 725 & 636 & 195 & 7 & & \\
\hline
\end{tabular}

\section{Hypothesis 3 - The preference for travel time is equal for main and auxiliary modes}

Testing the hypothesis that the preferences for travel time are equal for main and auxiliary modes involves models 3 and 4 , which differ in how the preference for travel time is modelled. Model 3 assumes the same parameter for all IVT, whilst model 4 differentiates between travel time in the main mode and travel time in an auxiliary mode. From this comparison we observe that the travel time parameters of main and auxiliary modes differ significantly, being higher for auxiliary modes. Hence, we reject the hypothesis that users have the same preference for travel time spent on the main mode and on auxiliary modes. 
Public Transport: One mode or several?

Table 5. LRT between models 3 and 4

\begin{tabular}{c|ccccc} 
& $\begin{array}{c}\text { Model } \\
\text { Number }\end{array}$ & $\begin{array}{c}\text { Final log- } \\
\text { likelihood }\end{array}$ & $\begin{array}{c}\text { Number of } \\
\text { parameters }\end{array}$ & LRT value & $\begin{array}{c}\text { LRT } \\
\text { P-value }\end{array}$ \\
\hline $\begin{array}{c}\text { Restricted model } \\
\begin{array}{c}\text { Unrestricted } \\
\text { model }\end{array}\end{array}$ & 3 & -2987.640 & 29 & 18.852 & $1.4 \mathrm{E}-05$
\end{tabular}

\section{Hypothesis 4 - IVT preferences are equal across main modes.}

Models 4 and 5 differ in how the preference for IVT within the main modes is modelled. Model 4 imposes the same IVT parameter for all main modes, whilst model 5 differentiates between main modes by implementing mode specific parameters. In this case, the LRT could not reject the hypothesis that the preference for IVT in the main mode is equal across different modes. As we can see in Table 8, the estimated parameters for IVT are similar for all PT main modes

Table 6. LRT between models 4 and 5

\begin{tabular}{c|ccccc} 
& $\begin{array}{c}\text { Model } \\
\text { Number }\end{array}$ & $\begin{array}{c}\text { Final log- } \\
\text { likelihood }\end{array}$ & $\begin{array}{c}\text { Number of } \\
\text { parameters }\end{array}$ & LRT value & $\begin{array}{c}\text { LRT } \\
\text { P-value }\end{array}$ \\
\hline $\begin{array}{c}\text { Restricted model } \\
\begin{array}{c}\text { Unrestricted } \\
\text { model }\end{array}\end{array}$ & 4 & -2978.214 & 30 & & \\
& 5 & -2978.040 & 33 & 0.348 & 0.9507
\end{tabular}

\section{Hypothesis 5 - IVT preferences are equal among auxiliary modes.}

Models 4 and 6 differ in how the preference for travel time within the auxiliary modes is modelled. Model 4 imposes the same travel time parameter for all auxiliary modes, whilst model 6 applies mode specific travel time parameters for auxiliary modes. At the levels of significance tested, the LRT could not reject the hypothesis that the disutility of in-vehicle auxiliary time is the same for all auxiliary modes.

Table 7. LRT between models 4 and 6

\begin{tabular}{c|ccccc} 
& $\begin{array}{c}\text { Model } \\
\text { Number }\end{array}$ & $\begin{array}{c}\text { Final log- } \\
\text { likelihood }\end{array}$ & $\begin{array}{c}\text { Number of } \\
\text { parameters }\end{array}$ & $\begin{array}{c}\text { LRT } \\
\text { value }\end{array}$ & $\begin{array}{c}\text { LRT } \\
\text { P-value }\end{array}$ \\
\hline $\begin{array}{c}\text { Restricted model } \\
\begin{array}{c}\text { Unrestricted } \\
\text { model }\end{array}\end{array}$ & 4 & -2978.214 & 30 & & \\
& 6 & -2975.116 & 33 & 6.196 & 0.1024
\end{tabular}


Table 8 - Estimation results

\begin{tabular}{|c|c|c|c|c|c|c|c|c|c|c|c|c|c|c|c|c|c|c|c|c|c|c|c|c|}
\hline Model No. & \multicolumn{3}{|c|}{1} & \multicolumn{3}{|c|}{2} & \multicolumn{3}{|c|}{3} & \multicolumn{3}{|c|}{4} & \multicolumn{3}{|c|}{5} & \multicolumn{3}{|c|}{6} & \multicolumn{3}{|c|}{7} & \multicolumn{3}{|c|}{7 -final ${ }^{* * *}$} \\
\hline Model type & \multicolumn{3}{|c|}{$\begin{array}{c}\text { ML } \\
(1000 \text { draws })\end{array}$} & \multicolumn{3}{|c|}{ MNL } & \multicolumn{3}{|c|}{ MNL } & \multicolumn{3}{|c|}{ MNL } & \multicolumn{3}{|c|}{ MNL } & \multicolumn{3}{|c|}{ MNL } & \multicolumn{3}{|c|}{ NL } & \multicolumn{3}{|c|}{ NL } \\
\hline Parameters & \multicolumn{3}{|c|}{33} & \multicolumn{3}{|c|}{29} & \multicolumn{3}{|c|}{29} & \multicolumn{3}{|c|}{30} & \multicolumn{3}{|c|}{33} & \multicolumn{3}{|c|}{33} & \multicolumn{3}{|c|}{32} & & 0 & \\
\hline Final log-likelihood: & -24 & 7.33 & & -24 & 25.48 & & -29 & 87.65 & & -29 & 78.21 & & & 78.04 & & & 75.12 & & -29 & 53.96 & & -29 & 4.18 & \\
\hline Rho-square & & 63 & & & 060 & & & 370 & & & 372 & & & 372 & & & 373 & & & 377 & & & 77 & \\
\hline Name & Value & t-test & & Value & t-test & & Value & t-test & & Value & t-test & & Value & t-test & & Value & t-test & & Value & t-test & & Value & t-test & \\
\hline ASC_BC & -0.799 & -2.33 & & -0.756 & -2.24 & & -0.62 & -1.79 & $*$ & -0.74 & -1.81 & & -0.63 & -1.83 & $*$ & -0.62 & -1.8 & $*$ & 40.736 & -2.13 & & -0.735 & -2.13 & \\
\hline ASC_BS & -0.003 & -0.01 & & 0.164 & 0.93 & * & - & - & & - & - & & - & - & & - & - & & - & - & & - & - & \\
\hline ASC_CD & 0.68 & 2.3 & & 0.638 & 2.30 & & 0.704 & 2.3 & & 0.519 & 2.42 & & 0.74 & 2.41 & & 0.728 & 2.37 & & 0.519 & 1.77 & $*$ & 0.507 & 1.73 & $*$ \\
\hline ASC_CP & -1.5 & -6.02 & & -1.48 & -6.23 & & -1.45 & -5.26 & & -1.33 & -5.21 & & -1.44 & -5.21 & & -1.44 & -5.22 & & -1.33 & -4.99 & & -1.32 & -5.00 & \\
\hline ASC_ME & 0.807 & 5.62 & & 0.743 & 6.08 & & 0.707 & 8.79 & & 0.615 & 9.27 & & 0.725 & 5.94 & & 0.821 & 9.47 & & 0.615 & 7.76 & & 0.801 & 2.23 & \\
\hline ASC_PT & - & - & $*$ & - & - & & -0.11 & -0.23 & $*$ & 0.003 & -0.35 & * & -0.12 & -0.26 & $*$ & -0.14 & -0.29 & $*$ & 0.003 & 0.01 & $*$ & 0.177 & 0.50 & $*$ \\
\hline ASC_TN & 0.391 & 2.11 & & 0.49 & 3.17 & & 0.259 & 2.18 & & 0.226 & 2.92 & & 0.407 & 2.15 & & 0.456 & 3.49 & & 0.226 & 2.14 & & 0.217 & 2.06 & \\
\hline ASC_TM & -1.36 & -2.59 & & -1.10 & -4.01 & & -2.16 & -5.47 & & -1.79 & -5.25 & & -1.98 & -3.22 & & -2.05 & -5.16 & & -1.79 & -5.18 & & -1.81 & -5.20 & \\
\hline BC_Winter & -1.72 & -4.54 & & -1.72 & -4.54 & & -1.76 & -4.65 & & -1.73 & -4.65 & & -1.76 & -4.65 & & -1.77 & -4.65 & & -1.73 & -4.57 & & -1.73 & -4.57 & \\
\hline BC_Woman & -0.673 & -2.32 & & -0.674 & -2.33 & & -0.716 & -2.46 & & -0.674 & -2.46 & & -0.715 & -2.45 & & -0.719 & -2.47 & & -0.674 & -2.33 & & -0.672 & -2.33 & \\
\hline CD_Comp & -1.19 & -4.55 & & -1.04 & -4.4 & & -1.05 & -4.49 & & -0.958 & -4.51 & & -1.06 & -4.5 & & -1.06 & -4.51 & & -0.958 & -4.89 & & -0.954 & -4.89 & \\
\hline CD_HHNumC & 0.807 & 7.36 & & 0.745 & 7.6 & & 0.731 & 7.41 & & 0.639 & 7.39 & & 0.73 & 7.37 & & 0.739 & 7.45 & & 0.639 & 7.16 & & 0.637 & 7.16 & \\
\hline CD_NoCar & -2.1 & -7.8 & & -1.82 & -7.72 & & -1.77 & -7.46 & & -1.71 & -7.44 & & -1.78 & -7.45 & & -1.76 & -7.38 & & -1.71 & -8.12 & & -1.72 & -8.14 & \\
\hline CD_Woman & -1.46 & -12.6 & & -1.32 & -13.1 & & -1.34 & -13.2 & & -1.21 & -13.1 & & -1.33 & -13.1 & & -1.34 & -13.1 & & -1.21 & -13.0 & & 1.21 & -13.0 & \\
\hline Cost0 & 0.0398 & 1.33 & $*$ & 0.0478 & 1.68 & $*$ & 0.023 & 0.65 & $*$ & 0.023 & 0.71 & $*$ & 0.022 & 0.6 & $*$ & 0.022 & 0.63 & $*$ & 0.023 & 0.66 & $*$ & - & - & \\
\hline Cost1 & 0.0283 & 0.6 & $*$ & 0.0299 & 0.64 & * & 0.026 & 0.5 & $*$ & 0.006 & 0.32 & * & 0.015 & 0.28 & $*$ & 0.018 & 0.34 & $*$ & 0.006 & 0.11 & $*$ & - & - & \\
\hline Cost2 & -0.027 & -1.39 & * & -0.024 & -1.34 & * & -0.04 & -1.63 & $*$ & -0.042 & -1.53 & * & -0.04 & -1.59 & * & -0.04 & -1.62 & $*$ & -0.042 & -1.78 & $*$ & -0.0520 & -2.91 & \\
\hline Cost3 & -0.036 & -2.7 & & -0.030 & -2.43 & & -0.039 & -2.09 & & -0.05 & -1.98 & & -0.04 & -2.04 & & -0.04 & -2.1 & & -0.05 & -2.67 & & -0.0589 & -4.70 & \\
\hline Cost4 & -0.027 & -2.12 & & -0.020 & -1.69 & $*$ & -0.034 & -1.83 & $*$ & -0.033 & -1.75 & * & -0.035 & -1.82 & $*$ & -0.035 & -1.86 & $*$ & -0.046 & -2.42 & & -0.0542 & -4.34 & \\
\hline CostMI & -0.053 & -3.15 & & -0.049 & -3.11 & & -0.05 & -2.08 & & -0.046 & -1.93 & $*$ & -0.049 & -1.99 & & -0.049 & -2.05 & & -0.051 & -2.2 & & -0.0618 & -4.01 & \\
\hline CP_NOCar & -1.14 & -5.54 & & -0.867 & -4.87 & & -0.798 & -4.45 & & $\mid-0.797$ & -4.44 & & -0.8 & -4.45 & & -0.795 & -4.42 & & -1.14 & -6.66 & & -1.14 & -6.73 & \\
\hline
\end{tabular}




\begin{tabular}{|c|c|c|c|c|c|c|c|c|c|c|c|c|c|c|c|c|}
\hline IVT_BC & -0.055 & -2.48 & -0.049 & -2.24 & -0.048 & -2.27 & $\mid-0.047$ & -2.25 & $\mid-0.048$ & -2.27 & $\mid-0.047$ & -2.24 & -0.048 & -2.3 & -0.0487 & -2.34 \\
\hline IVT_BS & - & - & - & - & - & - & - & - & -0.053 & -6.68 & -0.115 & -7.41 & - & - & - & - \\
\hline IVT_CD & -0.113 & -9.99 & -0.101 & -10.66 & -0.108 & -11.27 & -0.112 & -11.6 & -0.112 & -11.57 & -0.111 & -11.47 & -0.098 & -10.4 & -0.0954 & -10.94 \\
\hline IVT_CP & -0.1222 & -9.66 & -0.107 & -10.08 & -0.115 & -11.39 & -0.118 & -11.63 & -0.118 & -11.64 & -0.117 & -11.57 & -0.095 & -10.11 & -0.0937 & -10.17 \\
\hline IVT_ME & - & - & - & - & - & - & - & - & -0.05 & -5.29 & -0.076 & -5.53 & - & - & - & - \\
\hline IVT_PT & -0.064 & -6.84 & -0.056 & -7.07 & -0.057 & -7.6 & -0.052 & -6.88 & - & - & -0.053 & -7 & -0.05 & -7.1 & -0.0522 & -8.27 \\
\hline IVT_PT_AE & - & - & - & - & - & - & -0.093 & -8.05 & -0.094 & -7.94 & - & - & -0.087 & -8.18 & -0.0889 & -8.84 \\
\hline IVT_TM & - & - & - & - & - & - & - & - & -0.061 & $-1.52 *$ & -0.082 & -3.1 & - & - & - & - \\
\hline IVT_TN & - & - & - & - & - & - & - & - & -0.055 & -5.44 & -0.133 & -2.58 & - & - & - & - \\
\hline IVT_W & -0.044 & -6.13 & -0.041 & -5.93 & -0.039 & -5.26 & -0.039 & -5.28 & -0.04 & -5.3 & -0.039 & -5.26 & -0.04 & -5.46 & -0.0401 & -5.50 \\
\hline PT_AE & -0.040 & -3.94 & -0.037 & -4.03 & -0.049 & -6.41 & -0.053 & -6.83 & -0.053 & -6.75 & -0.055 & -6.99 & -0.046 & -6.67 & -0.0467 & -6.74 \\
\hline PT_FW & -0.039 & -4.75 & -0.037 & -5 & -0.028 & -3.93 & -0.028 & -3.91 & -0.028 & -3.89 & -0.025 & -3.57 & -0.026 & -4.11 & -0.0266 & -4.15 \\
\hline PT_XF & -0.034 & -5.22 & -0.032 & -5.56 & -0.037 & -8.6 & -0.036 & -8.42 & -0.036 & -7.97 & -0.035 & -8.18 & -0.029 & -7.51 & -0.0295 & -7.52 \\
\hline W_Apartm & 1.17 & 5.74 & 1.21 & 6 & 1.34 & 6.36 & 1.33 & 6.35 & 1.33 & 6.32 & 1.34 & 6.37 & 1.22 & 5.93 & 1.22 & 5.94 \\
\hline \multicolumn{17}{|l|}{ Error terms } \\
\hline Error_bus & 1.56 & 3.63 & - & - & - & - & - & - & - & - & - & - & - & - & - & - \\
\hline Error_Metro & 1.32 & 4.83 & - & - & - & - & - & - & - & - & - & - & - & - & - & - \\
\hline Error_Train & 1.15 & 3.21 & - & - & - & - & - & - & - & - & - & - & - & - & - & - \\
\hline Error_Tram & 1.06 & 1.15 & - & - & - & - & - & - & - & - & - & - & - & - & - & - \\
\hline \multicolumn{17}{|l|}{ Nests } \\
\hline N_CAR & - & - & - & - & - & - & - & - & - & - & - & - & 1.54 & $4.57^{* *}$ & 1.55 & $4.66^{* *}$ \\
\hline N_PT & - & - & - & - & - & - & - & - & - & - & - & - & 1.35 & $3.01^{* *}$ & 1.34 & $3.06^{* *}$ \\
\hline
\end{tabular}

* Parameter not statistically different from zero at $95 \%$ confidence

** Reported t-values for nesting parameters are in relation to the value 1 . Note that nesting parameter values must be not less than 1 to maintain consistency with utility maximisation.

*** Identical specification as model 7, but attributes with wrongly-signed parameters not statistically different from zero at $95 \%$ confidence level were removed. ASC remain in the specification to approximately reproduce market shares. 


\section{Hypothesis 6 - Public Transport modes have independent random errors.}

Comparing models 4 and 7, we observe a significantly better performance of the NL model, indicating that the correlation of the error components of the PT alternatives is higher than the correlation with the error components of the other modes.

Table 9. LRT between models 4 and 7

\begin{tabular}{c|ccccc} 
& $\begin{array}{c}\text { Model } \\
\text { Number }\end{array}$ & $\begin{array}{c}\text { Final log- } \\
\text { likelihood }\end{array}$ & $\begin{array}{c}\text { Number of } \\
\text { parameters }\end{array}$ & LRT value & $\begin{array}{c}\text { LRT } \\
\text { P-value }\end{array}$ \\
\hline $\begin{array}{c}\text { Restricted model } \\
\begin{array}{c}\text { Unrestricted } \\
\text { model }\end{array}\end{array}$ & 4 & 2978.214 & 30 & & \\
& 7 & -2953.955 & 32 & 48.518 & $1 \mathrm{E}-05$
\end{tabular}

Based on these findings, model 7 is the best of those tested. A further model, 7final, was estimated, also shown in Table 8, which removes wrongly-signed insignificant parameters and is more suitable for use in testing the model properties.

\section{MODEL PROPERTIES}

To confirm that the final model gives a reasonable representation of travel by commuters in Stockholm, we calculated the implied elasticities and values of time and compared those with established values.

\subsection{Aggregate price elasticities}

Aggregate direct price arc-elasticities for the different PT alternatives were calculated based on a model simulation with a $10 \%$ increase in the PT fare variable. The parameter estimates from model 7-final were used to compute elasticities, because this is the most suitable model. The arc elasticities are

$$
E_{x \rightarrow y}=\frac{\operatorname{LOG}\left(D_{y}\right)-\operatorname{LOG}\left(D_{x}\right)}{\operatorname{LOG}\left(P_{y}\right)-\operatorname{LOG}\left(P_{x}\right)}
$$

where $\mathrm{x}$ refers to the initial state, $\mathrm{y}$ to the new state, $\mathrm{D}$ is demand, $\mathrm{P}$ is price level and $\mathrm{E}$ is elasticity. Results show that among PT alternatives, the metro demand is the least price elastic $(-0.29)$, followed by bus $(-0.4)$, train $(-0.41)$ and tram $(-$ 1.43). These are values at the aggregate level, and individual elasticities can vary from these aggregated estimates. Since the sample population is reasonably representative of commuters in Stockholm, we can take these elasticities as roughly representative of Stockholm commuters.

Holmgren (2007) presents in its meta-analysis of public transport demand, fare elasticity values ranging from -0.009 to -1.32 , with a mean value of -0.38 . Similar values are reported by Kremers et al (2002) and DfT (2016), where the mean value for short run price elasticities is -0.4. This mean value is close to the price elasticities resulting from our model. Values of fare elasticities for PT commuting trips by the Swedish national model (Sampers) are -0.28, Börjesson and Kristoffersson (2017), 
whilst the Danish national passenger model reports a fare elasticity of -0.585 , Rich and Hansen (2016).

\subsection{Values of Time}

The Value of Time (VoT) is the sum of the marginal utility of time (the sum of the opportunity value of time and the direct utility of travel time) divided by the marginal utility of money (DeSerpa, 1971; Jara-Díaz, 2003). The VoT can be calculated from the model parameters as

$$
V o T_{i}=\frac{\partial V_{i} / \partial x_{\text {Time }}}{\partial V_{i} / \partial x_{\text {Cost }}} .
$$

In the particular case where the utility function is linear in both time and cost, which applies in model 7-final, the VoT is given by the ratio of the time and cost coefficients.

$$
V o T_{i}={ }^{\beta_{I V T_{i}}} / \beta_{\text {Cost }} \text {. }
$$

Table 10 shows the VoT estimates (SEK/h) for motorised transport modes, and compares values from models 4 (MNL) and 7 -final (NL). ${ }^{3}$ From these values we can observe three things. First, the VoT estimates obtained from the NL model follow the same pattern as the ones provided by the MNL model. Second, we observe from the estimates and t-values of the cost parameters in Table 8, how a more precise model reduces regression attenuation bias, achieving higher parameter estimates with increased t-values, particularly for the cost parameters. This translates to the smaller VoT estimates achieved by the NL model. Third, the values of time for the main modes given by the NL model are acceptably close to the reference values for the VoT in Sweden found in the literature. Börjesson and Eliasson (2013), provide the values shown in Table 11 (Euro/h) for short commute distance.

Table 10 - VoT estimates comparison for motorised modes.

\begin{tabular}{c|cccc} 
Model & $\begin{array}{c}\text { PT Main } \\
\text { Mode }\end{array}$ & $\begin{array}{c}\text { PT } \\
\text { Auxiliary } \\
\text { Mode }\end{array}$ & $\begin{array}{c}\text { Car } \\
\text { Driver }\end{array}$ & $\begin{array}{c}\text { Car } \\
\text { Passenger }\end{array}$ \\
\hline $4(\mathrm{MNL})$ & 81 & 146 & 175 & 185 \\
$7(\mathrm{NL})$ & 64 & 110 & 124 & 120
\end{tabular}

\begin{tabular}{c|c|cl} 
Mode & $\begin{array}{c}\text { Short } \\
\text { distance, } \\
\text { commute }\end{array}$ & $\begin{array}{c}\text { SEK } / \mathrm{h} \\
\left(2012 \text { rates }^{4}\right)\end{array}$ & \\
\cline { 1 - 3 } Car (Stockholm) & 12.1 & 105 & Table 11 - VoT estimates from the \\
Bus & 5.3 & 46 & Statest Swedish VoT study based on \\
Train & 7.2 & 63 & State data.
\end{tabular}

\footnotetext{
${ }^{3}$ VoT estimates are calculated using the weighted average value of the estimated cost parameters for the different income groups.

42012 average yearly conversion rate applied 1 SEK $=0,115$ Euro.
} 


\section{CONCLUSIONS}

In this paper, we present a methodology to investigate how the preference for different public transport modes varies among transport users. These are empirical findings for commuting trips in Stockholm, and whether these findings can be generalised to other cities is an empirical matter.

We find evidence that mode choice constants are significantly different among the PT modes. Hence, the average effect of the unobserved attributes differs significantly across the modes. Results suggest that, ceteris paribus, the preference for metro is highest and the preference for tram lowest.

Furthermore, we find that the value of time is higher for auxiliary modes than for the main mode. Nevertheless, we also find that systematic preferences among the PT alternatives are not proportional to the travel time. This suggests that the comfort is similar across the PT modes. SLL (2015) shows that all public transport modes suffer from crowding during the peak hour, although the crowding levels vary substantially between services within the system.

Regarding the existence of a rail factor, we find evidence to support the hypothesis that some rail-based modes - metro and commuter trains - have in fact a higher alternative specific constant, indicating that the average effect of the unobserved attributes makes them preferable to bus and tram, ceteris paribus.

We can reject the hypothesis that the PT modes have the same random error. This implies that, as long as we use MNL models, the model assuming that the public transport main modes are different alternatives outperforms the model assuming that they are the same alternative. In addition, we observe how the nested model outperforms the logit model with an identical utility specification, indicating that the error components of the PT alternatives are in fact correlated, confirming a priori expectations.

The simulated PT price elasticities yield values consistent with the international literature for bus, metro and train. The resulting values of time are also consistent with previous findings, suggesting the adequacy of the models.

Models able to capture and exploit nuances in the preferences for different PT alternatives may be important for policy analysis and detailed evaluation of infrastructure investments. Assuming travellers' preferences for different modes are equal, when in fact they are different will translate into biased parameter estimates and forecasts. This study shows how current state-ofpractice large-scale transport models can be enhanced to investigate these issues in further detail, and we find empirical evidence in our case study that supports both the manifest political preference for rail-based PT modes and Eliasson's (2016) finding that accessibility by metro increases the property prices of apartments in Stockholm more than accessibility by bus. 


\section{REFERENCES}

Axhausen, K. W., T. Haupt, B. Fell, and U. Heidl. 2001. Searching for the rail bonus: Results from a panel SP/RP study. European Journal of Transport and Infrastructure Research, 1(4): Pages 353-369.

Beale, J. R., and P. W. Bonsall. 2007. Marketing in the bus industry: A psychological interpretation of some attitudinal and behavioural outcomes. Transportation Research Part F, 10: Pages 271-287.

Ben-Akiva, M., Lerman, S. R. 1985. Discrete choice analysis: theory and application to travel demand, MIT Press.

Ben-Akiva, M., and T. Morikawa. 2002. Comparing ridership attraction of rail and bus. Transport Policy 2: Pages 107-116.

Bierlaire, M. 2016. PythonBiogeme: a short introduction. Report TRANSP-OR 160706, Series on Biogeme. Transport and Mobility Laboratory, School of Architecture, Civil and Environmental Engineering, Ecole Polytechnique Fédérale de Lausanne, Switzerland.

Börjesson, M., and Kristoffersson, I. 2017. The Swedish congestion charges: ten years on: - and effects of increasing charging levels. CTS working paper 2017:2. http://swopec.hhs.se/ctswps/abs/ctswps2017_002.htm

Börjesson, M., and Eliasson, J. 2014. Experiences from the Swedish Value of Time study, Transportation Research Part A: Policy and Practice, Volume 59, Pages 144-158.

Cain, A., J. Flynn, M. McCourt, and T. Reyes. 2009. Quantifying the importance of image and perception to bus rapid transit. Report FTA-FL-26-7109.2009.3, U.S. Department of Transportation, Washington D.C.

Cramer J.S. and Ridder G. 1991. "Pooling States in the Multinomial Logit Model", Journal of Econometrics, 47, Pages 267-272

Daly AJ; de Jong G; Brohm G. 1990. Vervoerswijzekeuzemodellen met carpooling (Mode Choice Models with Car-Pooling), Colloquim Vervoers-planologisch Speurwerk, Den Haag.

DeSerpa, A. (1971). A Theory of the Economics of Time. The Economic Journal, 81(324), 828-846. doi:10.2307/2230320"

DfT. 2016. Update to TAG Unit M2 to reflect updated values of travel time savings. Unit M2 - Variable Demand Modelling. https://www.gov.uk/government/uploads/system/uploads/attachment_data/f 
ile/542504/webtag-unit-m2-variable-demand-modelling-forthcoming-changenovember-2016.pdf

Eliasson, J. 2016. Förbättrade metoder för samhällsekonomisk analys av kollektivtrafikinvesteringar. CTS working paper 2016:6. http://www.transportportal.se/swopec/CTS2016-6.pdf

Fox, J. Daly, A. Patruni, B. 2009. "Improving the Treatment of Cost in Large Scale Models”. Association for European Transport paper repository.

Guiver, J.W. 2007. Modal talk: Discourse analysis of how people talk about bus and car travel. Transportation Research Part A 41: Pages 233-248.

Holmgren, J. 2007. Meta-Analysis of Public Transport Demand. Transportation Research A, Vol. 41, No. 10, pp. 1021-1035.

Jara-Díaz, S.R. 2003. On the goods-activities technical relations in the time allocation theory. Transportation 30: 245. doi:10.1023/A:1023936911351

Kremers, H., P. Nijkamp, and P. Rietveld. 2002. A Meta-Analysis of Price Elasticities of Transport Demand in a General Equilibrium Network. Economic Modelling, Vol. 19, No. 3, pp. 463-485.

Kristoffersson, Ida 2016. Nya efterfrågemodeller för färdmedels - och destinationsval i Sampers. Session 21 om trafikprognoser och efterfrågemo dellering. VTI-Transportforum, Linköping.

Ma L, Ye R and Titheridge H. 2014. 'Capitalization Effects of Rail Transit and BRT on Residential Property Values in a Booming Economy: Evidence from Beijing', Transportation Research Record, vol. 2451, Pages. 139-148.

Paulley, N., R. Balcombe R. Mackett, H. Titheridge, J. Preston, M. Wardman, J. Shires, and P. White. 2006. The Demand for Public Transport: The Effects of Fares, Quality of Service, Income and Car Ownership.Transport Policy, Vol. 13, No, 4, pp. 295-306.

Rich, J., Hansen, C.O. The Danish national passenger model - Model specification and results. 2016. European Journal of Transport and Infrastructure Research, $16(4)$, pp. 573-599.

Scherer, M. 2010. Is light rail more attractive to users than bus transit? Arguments based on cognition and rational choice. Transportation Research Record 2144: 11-19.

Scherer, M and Dziekan K. 2012. Bus or Rail: An Approach to Explain the Psychological Rail Factor. Journal of Public Transportation, 15 (1): Pages 75-93. 
SLL 2015. Information om genomförd utredning av trängseln i kollektivtrafiken. http://www.sll.se/Global/Politik/Politiska-organ/Trafiknamnden/2015/201504-14/p19-Info-TN-utredning-trangsel-i-kollektivtrafiken.pdf

Trafikanalys. 2007. '2005 - 2006 The National Travel Survey'. RES.

Trafikverket. 2015. Samhällsekonomiska principer och kalkylvärden för transportsektorn: ASEK 5.2. Kapitel 13 Operativa trafikeringskostnader för persontrafik.

http://www.trafikverket.se/contentassets/823481f052a74a3881492136383eb 01b/filer/13_trafikeringskostnad_person_a52.pdf

Vuchic, V. 2005. Urban Public Transport-Operations, Planning and Economics. New York: John Wiley and Sons.

Wardman, M. 2004. "Public transport values of time." Transport policy 11.4: 363-377.

\section{APPENDIX 1}

This appendix presents the explanatory variables entering the utilities of the models and gives an example of the full model specification.

Table 12 - Model 3 full specification.

\begin{tabular}{|c|c|c|c|c|c|}
\hline Parameter & Walk & Bicycle & PT & Car Driver & $\begin{array}{c}\text { Car } \\
\text { Passenger }\end{array}$ \\
\hline$A S C_{B C}$ & & 1 & - & & \\
\hline$A S C_{B U S}$ & - & - & 1 & - & - \\
\hline$A S C_{C D}$ & - & - & - & 1 & - \\
\hline$A S C_{C P}$ & - & - & - & - & 1 \\
\hline$A S C_{\text {METRO }}$ & - & - & 1 & - & - \\
\hline$A S C_{T R A I N}$ & - & - & 1 & - & - \\
\hline$A S C_{T R A M}$ & - & - & 1 & - & - \\
\hline$\beta_{B C_{-} T T}$ & - & bc_tt_min & - & - & - \\
\hline$\beta_{\text {BC_Winter }}$ & - & winter & - & - & - \\
\hline$\beta_{\text {BC_Woman }}$ & - & woman & - & - & - \\
\hline$\beta_{\mathrm{CD}_{-} \mathrm{Comp}}$ & - & - & - & ccomp & - \\
\hline$\beta_{\mathrm{CD}_{\text {HHNUMC }}}$ & - & - & - & carow & - \\
\hline$\beta_{\text {CD_NoCar }}$ & - & - & - & nocars & - \\
\hline$\beta_{\mathrm{CD} \_\mathrm{TT}}$ & - & - & - & c_tt_min & - \\
\hline$\beta_{\text {CD_Woman }}$ & - & - & - & woman & - \\
\hline$\beta_{\text {Costo }}$ & - & - & ptcost0 & cdcost0 & cpcost0 \\
\hline$\beta_{\text {Cost1 }}$ & - & - & ptcost1 & cdcost1 & cpcost 1 \\
\hline$\beta_{\text {Cost2 }}$ & - & - & ptcost2 & cdcost2 & cpcost2 \\
\hline$\beta_{\text {Cost3 }}$ & - & - & ptcost3 & cdcost3 & cpcost3 \\
\hline$\beta_{\text {Cost } 4}$ & - & - & ptcost 4 & cdcost 4 & cpcost 4 \\
\hline$\beta_{\text {CostMI }}$ & - & - & ptcost 9 & cdcost 9 & cpcost9 \\
\hline$\beta_{\text {CP_NoCar }}$ & - & - & - & - & Nocars \\
\hline$\beta_{\mathrm{CP}_{\mathrm{TT}} \mathrm{TT}}$ & - & - & - & - & c_tt_min \\
\hline$\beta_{\mathrm{PT}_{\mathrm{A}} \mathrm{AE}}$ & - & - & pt_ae & - & - \\
\hline$\beta_{\text {PT_FW }}$ & - & - & $\mathrm{pt} \_\mathrm{fw}$ & - & - \\
\hline$\beta_{\text {PT_ITT }}$ & - & - & pt_itt & - & - \\
\hline
\end{tabular}




\begin{tabular}{c|ccccc}
$\beta_{\mathrm{PT} \text { XF }}$ & - & - & pt_Xf & - & - \\
$\beta_{\mathrm{W}_{\text {_Apartm }}}$ & apartment & - & - & - & - \\
$\beta_{\mathrm{W} \_\mathrm{TT}}$ & wa_tt_min & - & - & - & -
\end{tabular}

apartment Dummy variable. It takes the value 1 if the user lives in an apartment and 0 otherwise

$b c_{-} t t_{-}$min $\quad$ Bicycle travel time in minutes

bs_ivt Bus In-vehicle travel time in minutes

bs_ivt_ae Access and egress in-vehicle travel time in minutes using the bus as auxiliary mode

carow Car ownership. The variable takes the minimum value between the number of cars in the household and the number of driver licenses.

ccomp Car competition dummy variable. It takes the value 1 if the number of cars in the household is less than the number of driver licenses and 0 otherwise.

cdcost Car driver costs in SEK. Costs are proportional to the distance travelled, multiplied by a factor that represents the marginal cost of travel by car ${ }^{5}$. Furthermore, different cost sharing assumptions have been tested using the formulation suggested by Fox, Daly and Patruni (2009).

$$
\begin{gathered}
V(\operatorname{Cos} t)_{C D}=\beta_{\text {Cost }} \operatorname{CarCost}_{O D}\left(1-\frac{S\left(O_{C D}-1\right)}{O_{C D}}\right) \\
V(\operatorname{Cos} t)_{C P}=\beta_{\text {Cost }} \operatorname{CarCost}{ }_{O D}\left(\frac{S}{O_{C P}}\right)
\end{gathered}
$$

where:

$S$ is the cost sharing factor

$O_{C D}$ is the mean occupancy for car driver observations

$O_{C P}$ is the mean occupancy for car passenger observations

Final parameters used in the case study are $S=1, O_{C D}=1.17$ and $O_{C P}=1.55$.

The cost variable is divided into 6 different income level groups. Level 0 includes observations with a reported income of 0 SEK. In Level 1 the reported income is between 1 and 9999 SEK. Level 2 includes observations with incomes between 10000 and 149999 SEK. Observations with a reported income between 150000 and 299999 SEK are included in Level 3. Level 4 includes observations with a reported income of 300000 SEK or higher. Finally, observations where income is not reported are included in "Level MI".

\footnotetext{
${ }^{5}$ Marginal cost of travel by car assumed $1.8 \mathrm{SEK} / \mathrm{km}$ as recommended by the Swedish Transport Authority (Trafikverket 2015).
} 
cpcost Car passenger costs in SEK. The cost for the passenger alternative is calculated following the same procedure described above.

The cost variable is divided into 6 different income level groups, as for the car driver alternative.

$c_{-} t t_{-} \min \quad$ Car travel time in minutes

me_itt Metro In-vehicle travel time in minutes

me_itt_ae Access and egress in-vehicle travel time in minutes using the metro as auxiliary mode

nocars Dummy variable. It takes the value 1 if the user's household do not own any car and 0 otherwise

ptcost Cost of the public transport alternative in SEK. The cost of the monthly ticket has been divided by 40 trips, assuming 4 weeks of 5 working days and 2 trips per day. Depending if the traveller is a student or not, the student or the full ticket has been used. No distinction has been made between the people who reported that they own a discount ticket and the ones who do not; this was done to prevent confirmation biases as PT for the people who normally commute by public transport will be cheaper than for others.

The cost variable is divided into 6 different income level groups, as for the car alternatives.

pt_ae Walking access and egress time in minutes

$p t \_$First waiting time in minutes

pt_ivt In-Vehicle travel time in minutes

$p t_{-} x f \quad$ Transfer time in minutes

tm_itt Tram In-vehicle travel time in minutes

tm_itt_ae Access and egress in-vehicle travel time in minutes using the tram as auxiliary mode

tn_itt Train In-vehicle travel time in minutes

$t n_{-} i t t_{-} a e \quad$ Access and egress in-vehicle travel time in minutes using the train as auxiliary mode

wa_tt_min Walking travel time in minutes

winter Dummy variable. It takes the value 1 if the trip has been made between weeks 47 and 14 and 0 otherwise

woman Dummy variable. It takes the value 1 if the user is a woman and 0 otherwise 


\section{APPENDIX 2}

This appendix presents results using only "pure observations", PT observations where only a single mode is used, versus observations divided using the main mode concept defined in Section 2.1.

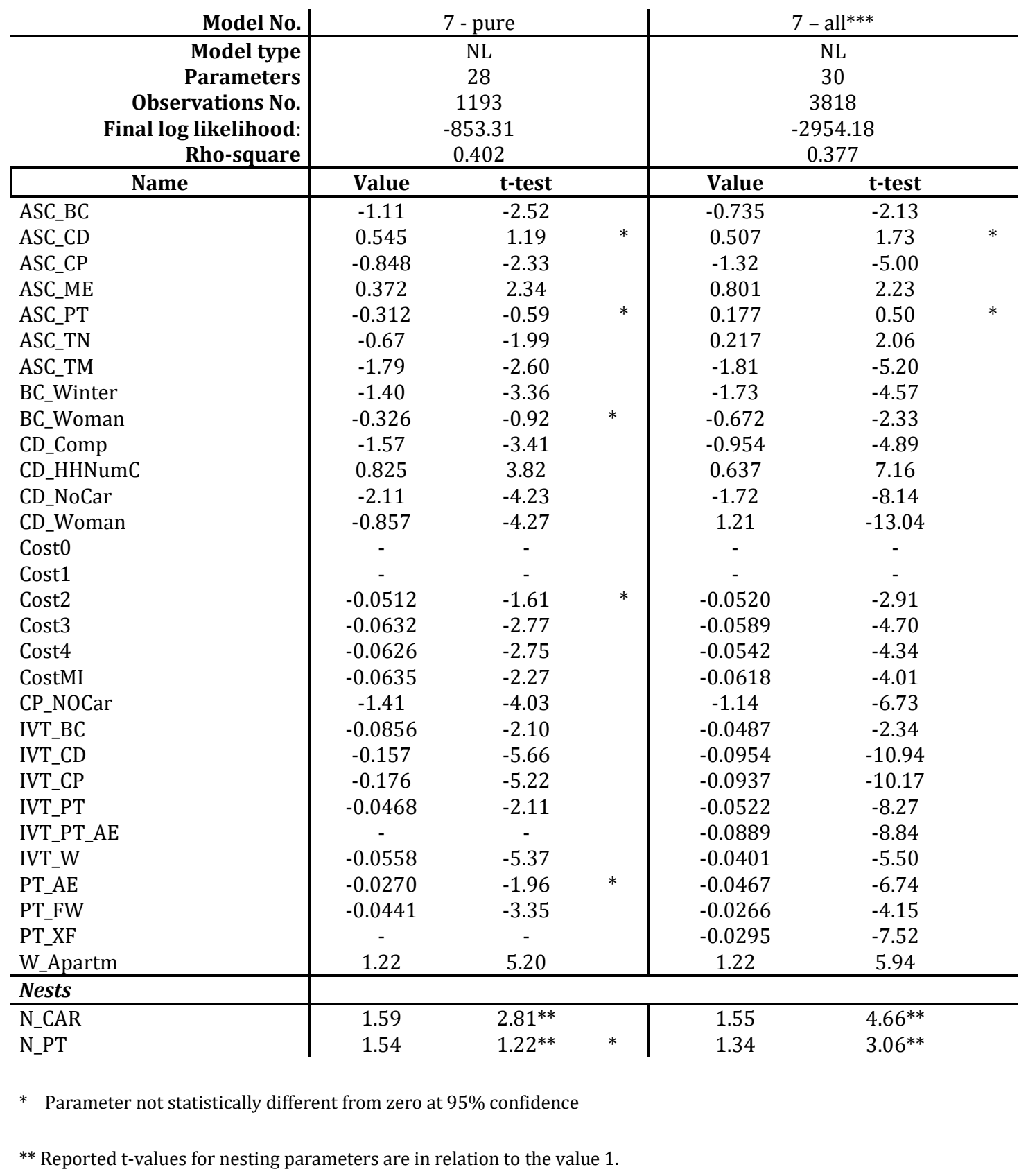

Note that nesting parameter values must be not less than 1 to maintain consistency with utility maximisation.

*** Identical specification as model 7, but attributes with wrongly-signed parameters not statistically different from zero at $95 \%$ confidence level were removed. ASC remain in the specification to approximately reproduce market shares. 